\title{
PENYUSUNAN PETA GEOGRAFISBERBASIS TATA RUANG DAN PEMANFAATAN WILAYAH DESA CINTARATU UNTUK OPTIMALISASI PERKEMBANGAN WILAYAH
}

\author{
Aulia Andhikawati, Asep Agus Handaka Suryana, dan Ibnu Bangkit Bioshina Suryadi \\ Fakultas Perikanan dan Ilmu Kelautan, Universitas Padjadjaran \\ E-mail: aulia.andhikawati@unpad.ac.id
}

\begin{abstract}
ABSTRAK. Desa Cintaratu memiliki luas lahan 1.029 Ha dengan pembagian lahan sebagai tempat pendidikan, pertokoan, lahan wisata dan lahan pertanian serta pemukiman. Optimalisasi pemanfaatan lahan harus diatur melalui perencanaan tata ruang yang disesuaikan dengan kondisi wilayah setempat agar tidak terjadi penyalahgunaan lahan di setiap Dusun. Berdasarkan hal tersebut maka perlu dilakukan penyusunan peta geografis berbasis tata ruang dan pemanfaatan wilayah Desa Cintaratu untuk optimalisasi perkembangan wilayah. Tujuan penelitian ini, yaitu untuk memetakan kondisi tata ruang dan pemanfaatannya berbasis potensi sumber daya alam dan mengidentifikasi potensi wilayah Desa Cintaratu. Metode yang digunakan yaitu wawancara mendalam kepada pejabat pemerintah terkait, BAPPEDA dan masyarakat desa Cintaratu, observasi lokasi/kawasan yang akan dikaji, serta mengkaji dan menganalisis data, dokumen, arsip dan lainnya yang berkaitan dengan pengembangan Desa Cintaratu. Hasil yang diperoleh yaitu: 1) Dusun Bontos memiliki potensi sebagai lini dagang dan lini pertanian dengan luas $80 \%$ dari total Sawah di Desa, 2) Dusun Cintasari memiliki potensi sebagai pusat dagang, 3) Dusun Sukamanah memiliki potensi sebagai pusat pendidikan, tempat usaha, pemukiman dan perkantoran, 4) Dusun Panglanjan sebagai tempat wisata alam dan perdagangan, dan 5) Dusun Gunung Tiga sebagai tempat pariwisata, yaitu wisata alam Jojogan dan pusat perdagangan. Berdasarkan hasil tersebut dapat disimpulkan bahwa pemanfaatan tata ruang dan wilayah Desa Cintaratu terdiri dari wilayah pertanian di Dusun Bontos, pemukiman di Dusun Sukamanah, pendidikan di Dusun Sukamanah, pariwisata di Dusun Gunung Tiga dan perdagangan yang tersebar di setiap Dusun.
\end{abstract}

Kata kunci: Desa Cintaratu; Tata Ruang; Pemanfaatan wilayah

ABSTRACT. Cintaratu district has a territorial area of about 1,029 hectares with the division of territorial area as places of education, commercial areas, tourism spots, agricultural and residential areas. Optimization of territorial utilization should be regulated through spatial and territorial planning adjusted to the local condition in order to avoid the misuse of territorial in each district. Based on this necessary to the preparation of geographic map based on spatial planning and territorial utilization in Cintaratu district area to optimize the development of the region. The purpose of this study, which is to map the spatial and utilization based on the potential of natural resources and identify potential Cintaratu district area. The method used is depth interviews with relevant government officials, BAPPEDA and Cintaratu community; observation location will be studied; as well as reviewing and analyzing data, documents, and other records relating to the development Cintaratu district. The results are: 1) Bontos Hamlet has potential as a line of commercial and agricultural with an area of $80 \%$ of the total agricultural field in Cintaratu, 2) Cintasari Hamlet has potential as a center of commerce, 3) Sukamanah Hamlet has potential as an educational center, a place of business, residential and office buildings, 4) Panglanjan Hamlet as natural tourist attractions and trades, and 5) Gunung Tiga Hamlet has tourism sites, namely Jojogan and trade center. Based on these results it can be concluded that spatial planning and territorial utilization in Cintaratu area consists of agricultural areas in the Bontos, Residential in Sukamanah, Education center in Sukamanah and tourism area in Gunung Tiga and commercial area are scattered in every hamlet.

Key words: Cintaratu district; Spatial Planning; Territorial Utilization

\section{PENDAHULUAN}

Pemanfaatan lahan di Desa Cintaratu saat ini merupakan hasil perencanaan ruang. Berdasarkan Permen PU No. 16/PRT/M/2009 menyatakan bahwa rencana tata ruang merupakan kesatuan geografis beserta unsur yang terkait yang batas dan sistemnya ditentukan berdasarkan aspek administratif. Perencanaan suatu wilayah mempunyai peranan penting dalam kegiatan pembangunan. Perencanaan pengembangan dan pemanfaatan suatu wilayah memerlukan visualisasi dalam bentuk pemetaan. Pemetaan berbasis tata ruang dilakukan karena ruang memiliki keterbatasan, sehingga diperlukan pengaturan dan perencanaan ruang agar dapat dimanfaatkan secara optimal dan efektif. Hasil dari perencanaan tata ruang wilayah dapat dituangkan dalam bentuk pemetaan geografis berbasis tata ruang dan pemanfaatan wilayah.

Hasil dari pemetaan tata ruang dan wilayah dapat berfungsi untuk pemanfaatan wilayah dan optimalisasi pengembangan wilayah sehingga dapat mencegah terjadinya konflik antar fungsi dari pemanfaatan ruang dan bahaya yang ditimbulkan akibat pengembangan fungsi ruang yang tidak sesuai dengan peruntukannya. Dokumen pemetaan ini perlu dilakukan evaluasi agar dokumen pemetaan ruang dapat berfungsi sesuai dengan tujuannya. Kebijakan dan strategi penataan ruang merupakan upaya mewujudkan tujuan dan sasaran pengembangan wilayah sekaligus mengatasi berbagai permasalahan pembangunan (Tikidi dan Haryanto, 2007) 
Berdasarkan UU No. 26 Tahun 2007 Tentang Penataan Ruang menyatakan bahwa penataan ruang pada dasarnya harus memperhatikan 4 (empat) aspek, yaitu: (1) potensi, (2) kondisi, (3) permasalahan sosial dan budaya, dan (4) kawasan rawan bencana. Berdasarkan data dari Badan Penanggulangan Bencana Daerah (BPBD) Kabupaten Pangandaran mencatat ada sebanyak 110 kejadian bencana alam sepanjang tahun 2018. Kabupaten Pangandaran merupakan daerah rawan bencana urutan ke-16 dari 514 Kabupaten/Kota se-Indonesia. Pada tingkat Wilayah Jawa Barat, Kabupaten Pangandaran berada pada urutan ke-5 daerah rawan bencana dari 27 Kabupaten/Kota di Jawa Barat. Bencana yang umumnya terjadi yaitu Banjir, tanah longsor dan angin kencang. Menurut Sagala dan Bisri (2011), adanya perencanaan tata ruang pada daerah rawan bencana merupakan bentuk pengendalian dalam pengembangan dan pembangunan wilayah rawan bencana.

Pada aspek ekonomi, perkembangan wilayah di Desa Cintaratu yang hanya terkonsentrasi pada salah satu Dusun akan merugikan kondisi ekologi setempat karena dapat menghambat perkembangan Dusun lain dan menimbulkan kesenjangan antar Dusun. Hal ini memberikan pengaruh negatif terhadap pemerataan pembangunan wilayah sehingga perlu dilakukan pengkajian terlebih dahulu sejauh mana potensi perkembangan wilayah agar diperoleh arah kebijakan dan pengembangan serta pemanfaatan wilayah yang tepat dan optimal. Berdasarkan hal tersebut, maka diperlukan penyusunan peta geografis berbasis tata ruang dan pemanfaatan wilayah Desa Cintaratu untuk optimalisasi perkembangan wilayah.

\section{METODE}

Kegiatan PPM ini merupakan kegiatan penelitian deskriptif dengan membuat gambaran dan menggali secara mendalam mengenai tata ruang dan pemanfaatan wilayah Desa Cintaratu. Analisis yang dilakukan yaitu analisis spasial dan disajikan dalam bentuk deskriptif eksploratif. Menurut Sukmana (2009), untuk melengkapi suatu analisis kualitatif maka harus diperkuat dengan data-data yang bersifat kuantitatif. Analisis kualitatif yaitu analisis secara deskriptif, sedangkan data kuantitatif berupa presentase dan bentuk tabulasi frekuensi.

Teknik pengambilan data melalui studi literatur dan survei lapangan. Menurut Sukmana (2009), teknik pengumpulan data yang digunakan dalam pengembangan wilayah menggunakan 3 (tiga) metode yang saling berkaitan dan melengkapi, yaitu: 1) In-depth interview, wawancara mendalam pada subjek maupun informan. Pada kegiatan ini yaitu pejabat pemerintah terkait, BAPPEDA dan masyarakat desa Cintaratu.
2) Observasi, dilakukan terhadap berbagai lokasi/ kawasan yang akan dikaji. Pada kegiatan ini dilakukan observasi terhadap lokasi/kawasan lindung dan budidaya.

3) Teknik dokumentasi, digunakan untuk mengkaji dan menganalisis data, dokumen, arsip dan lainnya yang berkaitan dengan pengembangan Desa Cintaratu.

Data yang digunakan didasarkan pada tiga indikator, yaitu :

1) Potensi perkembangan wilayah, yaitu indikator kependudukan, penggunaan lahan, infrastruktur, karakteristik sosial ekonomi.

2) Basis ekonomi wilayah, yaitu data struktur produksi wilayah Desa Cintaratu.

3) Kawasan yang dikelompokkan ke dalam kawasan lindung (lahan basah, lahan kering, pinggiran desa dan desa) dan budidaya (lindungan bawahan, lindungan setempat, cagar budaya, objek wisata) di Desa Cintaratu.

Analisis dilakukan secara deskriptif terhadap hasil pemetaan potensi dan perkembangan wilayah. Pemetaan tata ruang dan pemanfaatan wilayah desa dianalisis berdasarkan peruntukkan fungsi kawasan yang mengacu pada Peraturan Daerah Kabupaten Pangandaran Nomor 3 Tahun 2018 Tentang Tata Ruang Wilayah Kabupaten Pangandaran Tahun 2018-2038, yaitu kawasan lindung, resapan air, budidaya dan lain sebagainya.

\section{HASIL DAN PEMBAHASAN}

Desa Cintaratu terdiri dari 5 Dusun, yaitu Dusun Bontos, Dusun Cintasari, Dusun Sukamanah, Dusun Panglanjan, dan Dusun Gunung Tiga. Setiap dusun memiliki karakteristik Sumberdaya Alam, Sumberdaya Manusia serta fasilitas yang berbeda, yaitu:

1) Dusun Bontos, mayoritas mata penchariannya merupakan petani,

2) Dusun Cintasari memiliki lahan kosong yang kemudian digunakan untuk menanam kacangkacangan dan sayur-sayuram,

3) Dusun Sukamanah, dusun ini memilki fasilitas yang lebih lengkap dibanding dusun lainnya, dimana di dusun ini juga kantor Kecamatan Parigi berada, untuk fasilitas pendidikannya pun terdapat TK, SD, SMP, SMK, dan Perguruan Tinggi Negeri PSDKU Unpad di Pangandaran,

4) Dusun Panglanjan, di dusun ini kami menjumpai banyak sekali lereng-lereng dan juga perkebunan seperti kelapa, dan yang terakhir 5) Dusun Gunung Tiga, di dusun ini terdapat daerah wisata yang sangat berpotensi dan cukup menjadi favorit di Pangandaran itu sendiri. 
Rencana Pembangunan Desa Cintaratu terbagi menjadi dua yaitu, Rencana Pembangunan Desa Jangka Menengah (RPJM) dan Rencana Kerja Pembangunan (RKP). RPJM dilakukan setiap 6 bulan sekali. Pembangunan setiap dusun mengacu pada visi dan misi dusun. Pembangunan jangka menengah ini ditetapkan secara musyawarah melalui musyawarah desa. Sedangkan Rencana Kerja Pembangunan dilaksanakan setiap tahun yang ditetapkan melalui musyawarah desa. Adapun kendala dalam pelaksanaan pembangunan, yaitu sumber dana yang belum mencukupi dan kurangnya kemampuan masyarakat dalam pengembangan potensi desa. Proses Pembangunan yang telah dilaksanakan di Desa Cintaratu yaitu akses jalan yang sudah diperbaiki, adanya pembangunan pusat pendidikan hingga universitas,dan perkantoran.

Potensi-potensi dan Pengembangan wilayah Desa Cintaratu yakni sebagai berikut:

\section{Dusun Bontos}

Berdasarkan data lini usaha dan data infrastruktur, karakteristik Dusun Bontos yaitu:Sawah Cintaratu Seluas 288,61 Ha dan $80 \%$ berada di Dusun Bontos, adanya kelengkapan alat untuk pertanian, pengairan berasal dari aliran Citumang, penduduk didominasi oleh petani, dan terdapat kebun Buah Naga yang masih dalam pengembangan. Pengembangan Dusun Bontos yaitu:

Lini pertanian: Dusun Bontos memiliki luas lahan tani yang luas serta di dukung oleh aliran air dari irigasi yang baik, maka dusun bontos memiliki potensi yang sangat baik di lini pertanian.

Lini Dagang: Dusun Bontos memiliki akses jarak yang sangat dekat dari jalan provinsi dan jalan
Desa, berkat itu bontos mempunyai potensi yang cukup baik di sektor dagang seperti warung,tempat makan, dan lain sebagainya.

\section{Dusun Cintasari}

Berdasarkan data lini usaha dan data infrastruktur, Dusun Cintasari memiliki banyak lahan kosong dan sulit untuk pengairan sawah sehingga lahan sawah tidak bisa dimanfaatkan. Pengembangan Dusun Cintasari yaitu :

Lini Dagang: Dusun Cintasari berdekatan dengan 2 lembaga pendidikan dan dilalui oleh jalan kabupaten yang merupakan akses utama untuk menuju pada pusat desa cintaratu.

\section{Dusun Sukamanah}

Berdasarkan data lini usaha dan data infrastruktur, potensi Dusun Sukamanah, yaitu sebagai Pusat Pemerintahan, Pendidikan dan Usaha. Halini dikarenakan adanya pusat pendidikan dari TK/ PAUD hingga perguruan tinggi dan terdapat kantor pemerintahan yaitu Kantor Kecamatan. Pengembangahn Dusun Sukamanah, yaitu :

Lini Dagang: Dusun Sukamanah berada di pusat desacintaratudanjugaberdekatan dengan 2lembaga pendidikan yaituPSDKU Unpad Pangandaran dan SMK, maka mempunyai potensi yang sangat bagus seperti membuka cafe, warnet, tempat makan, koskosan dan hal-hal yang di butuhkan oleh banyak orang, khususnya mahasiswa.

\section{Dusun Panglanjan}

Dusun Panglanjan memiliki wilayah yang didominasi oleh lereng dengan jumlah berkisar 13 lereng dan dapat dijadikan Perkebunan Kelapa. Dusun ini bisa dikatakan kurang memiliki potensi yang baik di lini pertanian dan peternakan. Hal ini dikarenakan infrastruktur yang ada itu memang
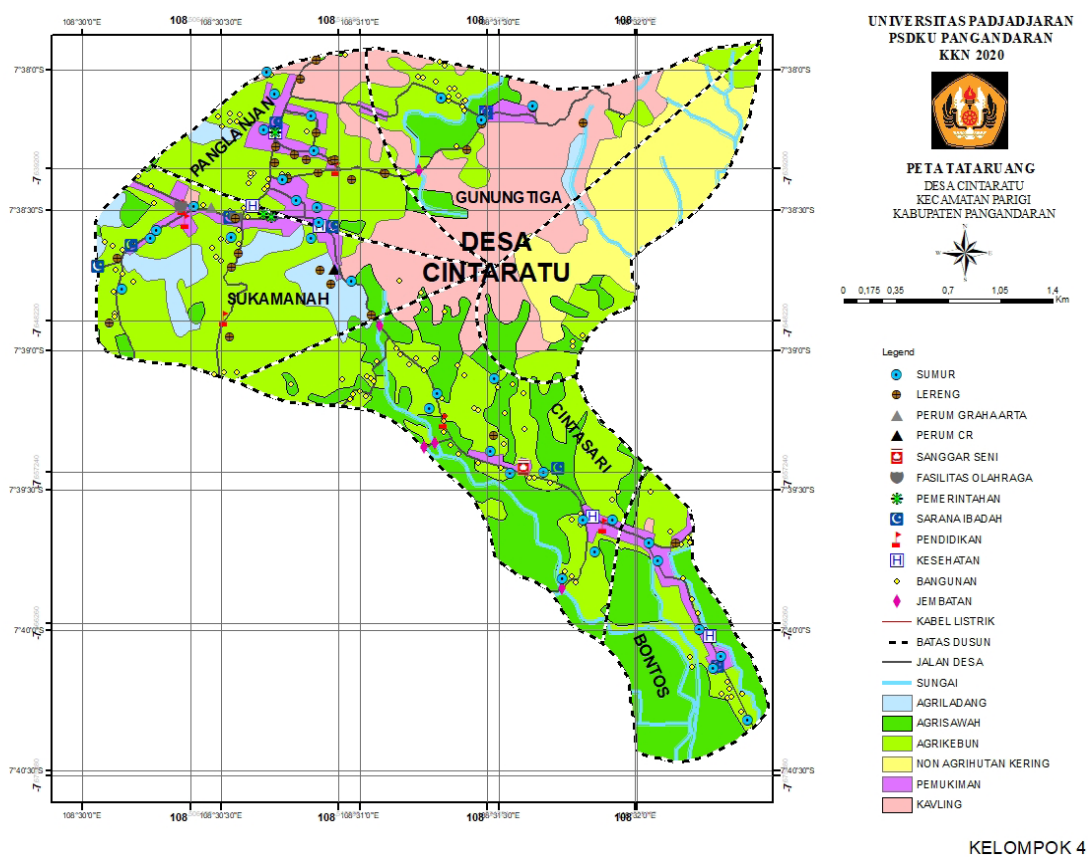

Gambar 1. Peta Potensi Desa Cintaratu 
tidak bisa mendukung adanya potensi usaha tersebut, namun ada satu yang cukup baik, yaitu:

Lini Dagang: Dusun Panglanjan dilalui oleh jalan kabupaten, namun itu merupakan jalur cepat sehingga potensi usaha mikro seperti pom mini, rumah makan dan toko kelontong menjadi sumber penghasilan untuk masyarakat di desa tersebut.

\section{Dusun Gunung Tiga}

Dusun ini mempunyai 2 potensi usaha yang bisa di kembangkan, yaitu:

Lini pariwisata: DusunGunung Tiga memiliki lokasi wisata yang cukup terkenal yaitu wisata alam Jojogan.Wisata alam tersebut memiliki potensi yang sangat besar untuk dijadikan sumber penghasilan bagi warga dusun tersebut.

Lini dagang: Adanya lokasi wisata yang cukup terkenal, maka keberadaan tempat usaha seperti rumah makan, penginapan dan toko souvenir serta pom minimemiliki potensi sebagai sumber usaha untuk warga dusun tersebut.

\section{SIMPULAN}

Simpulan yang didapatkan dari kegiatan ini, yaitu: Pemanfaatan lahan terbuka Desa Cintaratu berada pada Dusun Bontos sebagai lahan pertanian, Dusun Panglanjan sebagai lahan perkebunan, dan Gunung Tiga sebagai tempat wisata alam; Potensi setiap Dusun, yaitu : 1) Dusun Bontos memiliki potensi sebagai lini dagang dan lini pertanian, 2) Dusun Cintasari memiliki potensi sebagai pusat dagang, 3) Dusun Sukamanah memiliki potensi sebagai pusat pendidikan, tempat usaha, pemukiman dan perkantoran, 4) Dusun Panglanjan sebagai tempat wisata alam dan perdagangan, dan 5) Dusun Gunung Tiga sebagai tempat pariwisata dan pusat perdagangan.

\section{UCAPAN TERIMAKASIH}

Ucapan terima kasih kami sampaikan kepada berbagai pihak khususnya kepada DRPMI Universitas Padjadjaran yang telah memberikan dana dan kepada Pemerintah Kabupaten Pangandaran, serta warga Desa Cintaratu, atas partisipasi dan dukungannya selama pelaksaan kegiatan.

\section{DAFTAR PUSTAKA}

Bafdal, N., Balia, R.L., Dwiratna, S., dan Amaru, K. 2014. Penyusunan Peta Potensi Desa Agrowisata Berbasis Masyarakat di Desa Cibuntu Kecamatan Pasawahan Kabupaten Kuningan. Dharmakarya, 3 (2) : 81-87.

Haryanto dan Tukidi. 2007. Konsep Pengembangan Wilayah dan Penataan Ruang Indonesia di Era Otonomi Daerah. Jurnal Geografi, 4(1) : 1-10.

Muta'al, L. 2005. Potensi Perkembangan Wilayah dan Kaitannya dengan Tata Ruang di Kawasan Lereng Merapi Provinsi Daerah Istimewa Yogyakarta. Majalah Geografi Indonesia, Vol. 19. No. 1.

Pemerintah Kabupaten Pangandaran. 2019. Profil Pangandaran. (https://dev.pangandarankab. go.id/public/profile, diakses 3 Februari 2020).

Peraturan Daerah Kabupaten Pangandaran Nomor 3 Tahun 2018 Tentang Rencana Tata Ruang Wilayah Kabupaten Pangandaran Tahun 2019-2038.

Sukmana, O. 2009. Model Pengembangan Lingkungan Kota Ekowisata (Studi Wilayah di Kota Batu). Jurnal Humanity, 5(1) : 42-47. 